\title{
Umbilical Cord Blood Biomarkers of Neurologic Injury and the Risk of Cerebral Palsy or Infant Death
}

\author{
Maged M. Costantine, M.D., Steven J. Weiner, M.S., Dwight J. Rouse, M.D., Deborah G. \\ Hirtz, M.D., Michael W. Varner, M.D., Catherine Y. Spong, M.D., Brian M. Mercer, M.D., Jay \\ D. lams, M.D., Ronald J. Wapner, M.D., Yoram Sorokin, M.D., John M. Thorp Jr., M.D., \\ Susan M. Ramin, M.D., Mary J. O'Sullivan, M.D., Alan M. Peaceman, M.D., and Hyagriv N. \\ Simhan, M.D. for the Eunice Kennedy Shriver National Institute of Child Health and Human \\ Development Maternal-Fetal Medicine Units Network \\ Department of Obstetrics and Gynecology at the University of Texas Medical Branch, Galveston, \\ TX (M.M.C.); University of Alabama at Birmingham, Birmingham, AL (D.J.R.); University of Utah, \\ Salt Lake City, UT (M.W.V.); Case Western Reserve University-MetroHealth Medical Center, \\ Cleveland, $\mathrm{OH}$ and University of Tennessee, Memphis, TN (B.M.M.); The Ohio State University, \\ Columbus, $\mathrm{OH}$ (J.D.I.); Thomas Jefferson University and Drexel University, Philadelphia, PA \\ (R.J.W.); Wayne State University, Detroit, MI (Y.S.); University of North Carolina at Chapel Hill, \\ Chapel Hill, NC (J.M.T.); University of Texas Health Science Center at Houston, Houston, TX \\ (S.M.R.); University of Miami, Miami, FL (M.J.O.); Northwestern University, Chicago, IL (A.M.P.); \\ University of Pittsburgh, Pittsburgh, PA (H.N.S.); and The George Washington University \\ Biostatistics Center, Washington, DC (S.J.W.); the National Institute of Neurological Disorders \\ and Stroke, Bethesda, MD (D.G.H.); and the Eunice Kennedy Shriver National Institute of Child \\ Health and Human Development, Bethesda, MD (C.Y.S.)
}

\section{Abstract}

To evaluate the association between cerebral palsy (CP) or infant death and putative cord blood biomarkers of neurologic injury, we performed a nested case-control secondary analysis of a multicenter randomized trial of magnesium sulfate $\left(\mathrm{MgSO}_{4}\right)$ versus placebo to prevent $\mathrm{CP}$ or death among offspring of women with anticipated delivery from $24-31$ weeks' gestation. Cases were infants who died by 1 year $(n=25)$ or developed CP $(n=16)$, and were matched 1:2 to a control group $(n=82)$ that survived without developing CP. Umbilical cord sera concentrations of S100B, neuron-specific enolase (NSE) and the total soluble form of the receptor for advanced glycation end-products (sRAGE) were measured by ELISA in duplicates. Maternal characteristics were similar between the 2 groups. Cases were born at a lower gestational age (GA) and had lower birth weight compared with controls. There were no differences in concentrations of the three biomarkers and the composite outcome of CP or infant death. However, S100B was higher (median 847.3 vs. $495.7 \mathrm{pg} / \mathrm{ml}$; $\mathrm{p}=0.03$ ) in infants who had CP and total sRAGE was lower (median 1259.3 vs. $1813.1 \mathrm{pg} / \mathrm{ml}$; $\mathrm{p}=0.02$ ) in those who died compared with the control group. When corrected for delivery GA and treatment group, both differences lost statistical significance.

(C) 2011 ISDN. Published by Elsevier Ltd. All rights reserved.

Corresponding author: Maged Costantine MD, 301 University Blvd, Galveston, TX 77555-0587, Phone 409-772-1571, Fax 409-772-5297, mmcostan@utmb.edu.

*The other members of the Eunice Kennedy Shriver National Institute of Child Health and Human Development (NICHD) MaternalFetal Medicine Units Network are listed in the Appendix.

Conflicts of Interest: none to disclose by all authors

Publisher's Disclaimer: This is a PDF file of an unedited manuscript that has been accepted for publication. As a service to our customers we are providing this early version of the manuscript. The manuscript will undergo copyediting, typesetting, and review of the resulting proof before it is published in its final citable form. Please note that during the production process errors may be discovered which could affect the content, and all legal disclaimers that apply to the journal pertain. 
In conclusion, cord blood S100B level may be associated with $\mathrm{CP}$, but this association was not significant after controlling for $\mathrm{GA}$ and $\mathrm{MgSO}_{4}$ treatment.

\section{Keywords}

cerebral palsy; infant death; umbilical cord biomarkers; neuroprotection; pregnancy

\section{Introduction}

Cerebral palsy $(\mathrm{CP})$ is characterized by aberrant control of movement or posture appearing early in life, and not the result of recognized progressive disease (ACOG \& AAP, 2003). Currently, it is estimated that the prevalence of CP is 1.5 to 2.5 per 1000 live births (Paneth et al., 2006). These numbers have been stable despite the advances in neonatal and perinatal care which resulted in reductions in mortality of extremely premature infants (Paneth et al., 2006; Winter et al., 2002). The leading risk factor for CP as well as perinatal and infant death is prematurity with both $\mathrm{CP}$ and death rates inversely proportional to the gestational age (GA) at birth (Saigal and Doyle, 2008).

A definite etiology for $\mathrm{CP}$ is never found for the majority of cases. It has been hypothesized that $\mathrm{CP}$ is the result of neuronal injury or insult to the developing brain secondary to inflammatory, hypoxic, excitatory, or oxidative injury; and that the timing of that insult is in the prenatal or perinatal period in about $70 \%$ of the cases in infants born preterm and $85 \%$ in those born at term (Hagberg et al., 2001). Although CP is generally not diagnosed until the second year of life or later, it is possible that biomarkers present at birth could predict the risk of its development (or non-development). If such prediction were possible, neonates who are at highest risk and who would benefit most from any neuroprotective therapies might be identified (Perlman, 2006).

Some of these potential markers are brain-specific and are elevated in the serum after brain injury. Examples include the calcium binding protein S100B and neuron-specific enolase (NSE) (Marchi et al., 2004; Nagdyman et al., 2001; Nguyen et al., 2006; Park et al., 2004; Ramaswamy et al., 2009; Thorngren-Jerneck et al., 2004). Others, such as the advanced glycation endproducts (AGEs) or their receptor (RAGE), are associated with the activation of the fetal inflammatory processes that potentiate tissue injury (Buhimschi et al., 2009; Ramaswamy et al., 2009). Direct inflammatory mediators such as the various interleukins, TNF- $\alpha$, and others are also involved (Buhimschi et al., 2009; Kaukola etal., 2004;

Ramaswamy et al., 2009). The biology of the RAGE pathway is complicated and dependent on its ligands as well as on a soluble truncated form of the receptor (sRAGE) which acts as a decoy receptor and an inhibitor of the native receptor (Buhimschi et al., 2009). It has been shown that S100B, a brain specific marker of neurologic injury, interacts with RAGE to amplify its downstream signal leading to accelerated cellular injury, and that activation of the RAGE pathway in the setting of fetal inflammation is associated with reduced levels of its soluble truncated form (i.e. sRAGE) (Buhimschi et al., 2009).

We hypothesized that, in neonates subsequently diagnosed with CP, select biomarkers of brain injury in umbilical cord blood could differentiate neonates with $\mathrm{CP}$ from those who survived without $\mathrm{CP}$. Because death would preclude the diagnosis of $\mathrm{CP}$, we also included death in the outcome. Thus, the objective of our study was to evaluate the association between infant death by 1 year of corrected age or the diagnosis of $\mathrm{CP}$ and potential umbilical cord blood markers of fetal neurologic injury. Additionally, we intended to test whether the relationship between these biomarkers and the outcomes (CP, death, and the two combined) was modified by antenatal exposure to magnesium sulfate $\left(\mathrm{MgSO}_{4}\right)$. 


\section{Materials \& Methods}

\subsection{Study Design}

This was a secondary analysis and a nested case-control study of the Eunice Kennedy Shriver National Institute of Child Health and Human Development (NICHD) MaternalFetal Medicine Units Network "Randomized Clinical Trial of the Beneficial Effects of Antenatal Magnesium Sulfate", in which women who had singleton or twin gestations between 24-31 $6 / 7$ weeks' gestation and at high risk for imminent preterm birth were randomized to receive either magnesium sulfate $\left(\mathrm{MgSO}_{4}\right)$ infusion or placebo (Rouse et al., 2008). Women were enrolled at 20 institutions between December 1997 and May 2004. For this analysis, cases were infants who died by 1 year of corrected age or were diagnosed with $\mathrm{CP}$ at or beyond 2 years of corrected age. The control group included infants who survived until 2 years of age without CP. Subjects enrolled in the trial and who had available umbilical cord blood serum and two-year data on neurological outcomes or death were included. We excluded cases of fetal demise and neonates with major congenital malformations or genetic syndromes. Cases were matched at a ratio of 1:2 to controls for ethnicity/race, infant gender, and number of fetuses. The primary outcome of the study was a composite of infant death by 1 year or development of CP (any severity) among survivors as assessed at 24-28 months of life (corrected for prematurity). The secondary outcomes analyzed included infant death by 1 year of age and CP (any severity). Because of the limitation in our sample size, we did not perform a subgroup analysis for moderate-severe or mild CP. Details about the definitions and diagnoses of these selected outcomes are described elsewhere (Rouse et al., 2008).

\subsection{Laboratory testing}

Venous umbilical cord blood was obtained in a red top tube and centrifuged for 10 minutes (3400 RPM) within 2 hours of birth. Serum was aliquoted and stored at -70C. All samples available from the original study were shipped on dry ice for batch analysis in a single lab at the University of Texas Medical Branch in Galveston, Texas. Personnel performing the laboratory analysis were blinded to case/control status.

Umbilical cord serum neuron-specific enolase (NSE), S100 calcium binding protein B (S100B) and the total soluble form of the receptor for advanced glycation end-products (sRAGE) were measured with commercially available enzyme-linked immunosorbent assay (ELISA) kits and according to the manufacturer's recommendations. Grossly hemolyzed samples $(\mathrm{n}=12)$ were not included in NSE analysis. Immunoassay kits for NSE, S100B and sRAGE were purchased from Alpha Diagnostic International (San Antonio, TX, USA), BioVendor, LLC (Chandler, NC, USA) and R\&D Systems (Minneapolis, MN, USA) respectively. The detection limits for the 3 assays are $1 \mu \mathrm{g} / \mathrm{L}, 5 \mathrm{pg} / \mathrm{mL}$, and $4.1 \mathrm{pg} / \mathrm{mL}$ respectively. The inter- and intra-assay coefficients of variation were $<10 \%$ for all analytes. All samples were run in duplicate and the mean values used in analyses.

\subsection{Statistical Analysis}

Statistical analyses were performed using SAS statistical software (SAS Institute, Cary, NC). Maternal and neonatal continuous variables were compared with the use of the Wilcoxon ranksum test, and categorical variables with the chi-square or Fisher's exact test. Biomarker concentrations were analyzed both as continuous and categorical variables. Data were divided into categories using the $75^{\text {th }}$ percentile (S100B and NSE) or the $25^{\text {th }}$ percentile (sRAGE) of control samples from patients in the placebo group $(n=43)$. We had nearly $80 \%$ power to detect an odds ratio of 3.0 in the primary outcome of interest using these thresholds and the available sample size. Logistic regression was used to analyze the association between biomarker concentrations and neonatal outcomes, while including the 
effect of delivery GA and study treatment group. Similarly, we studied the effect of latency after preterm premature rupture of membranes (pPROM) on the relationship between neonatal outcomes and biomarker concentrations. We did not adjust for multiple comparisons. A two-sided P-value of less than 0.05 was considered to indicate statistical significance, and no adjustments were made for multiple comparisons.

\section{Results}

41 infants who developed $\mathrm{CP}(\mathrm{n}=16)$ or infant death $(\mathrm{n}=25)$ and met all study criteria were matched by race, infant gender, and number of fetuses to 82 controls. Infants with serum available for testing were similar for maternal characteristics, but were on average 204 grams heavier at birth and were born one week later in gestation. This difference is likely related to the difficulty of obtaining sufficient cord blood from the smallest neonates. Maternal and neonatal characteristics for the analyzed cohort are summarized in Tables 1 and 2. Neonates who died or had CP weighed less at birth and were born at earlier gestational ages compared with the control group. In addition they had lower Apgar scores at one and 5 minutes and were more likely to have had neonatal sepsis. On the other hand, there were no significant differences between cases and controls in such maternal characteristics as preterm premature rupture of membranes (pPROM), clinical chorioamnionitis, mode of delivery or treatment allocation (i.e. $\mathrm{MgSO}_{4}$ or placebo).

There were no differences in S100B, NSE or total sRAGE concentrations between infants who died or developed $\mathrm{CP}$ and controls, nor in the percentage of them who had highest quartile concentrations of S100B (above $871.5 \mathrm{pg} / \mathrm{mL}$ ) or NSE (above $20.8 \mu \mathrm{g} / \mathrm{L}$ ), or lowest quartile sRAGE concentration (below $1058.5 \mathrm{pg} / \mathrm{mL}$ ). The odds of developing the combined outcome, adjusted for delivery GA and study treatment group, for those infants who had biomarker concentrations in these quartiles were not significantly increased (Table 3).

We then performed analyses for the individual outcomes of CP (Table 4) and death (Table 5). Umbilical cord serum concentrations of S100B were significantly higher in neonates who developed CP compared with the control group (median 847.3 vs. $495.7 \mathrm{pg} / \mathrm{mL} ; \mathrm{p}=0.03$ ), however that difference became statistically non-significant when adjusted for GA at delivery and treatment group $(\mathrm{p}=0.51)$. Cord serum concentrations of sRAGE were significantly lower in those who died than in controls (median 1259.3 vs. $1813.1 \mathrm{pg} / \mathrm{mL}$; $\mathrm{p}=0.02)$, and also more cases had sRAGE concentrations in the lowest quartile $(44.0 \%$ vs. $19.8 \%, \mathrm{p}=0.02$ ), respectively, but those differences also lost significance when corrected for GA at delivery and treatment allocation (OR 2.19, 95\% CI $0.77-6.19 ; \mathrm{p}=0.14)$.

We also tested whether the relationship between the biomarkers and each outcome $(\mathrm{CP}$, death, and the two combined) was modified by $\mathrm{MgSO}_{4}$ treatment. After adjusting for GA at delivery, we did not find any significant interaction in our models between any of the biomarkers and $\mathrm{MgSO}_{4}$ treatment (P-values for interaction: 0.16 - 0.81; data not included), and there were no significant differences in the biomarker concentrations between neonates who received $\mathrm{MgSO}_{4}$ and those who received placebo. (Table 6) Additionally, we did not find any significant effect of latency after pPROM on the relationship between the neonatal outcomes and biomarker concentrations.

\section{Discussion}

In this group of high risk neonates, in univariable analyses, umbilical cord blood concentrations of S100B and total sRAGE were associated with the diagnosis of $\mathrm{CP}$ and perinatal death, respectively. However, after controlling for the $\mathrm{GA}$ at birth and $\mathrm{MgSO}_{4}$ treatment allocation, none of the umbilical cord blood biomarkers studied were associated 
with infant death or development of $\mathrm{CP}$, or any of the secondary outcomes. Moreover, no association was found between $\mathrm{MgSO}_{4}$ treatment and the biomarker concentrations.

We chose to investigate 3 potential markers of neonatal neurologic injury because of their reported associations with adverse neonatal outcomes. S100B is a calcium-binding protein, predominantly expressed and released by astrocytes in the central nervous system. It is involved in intracellular calcium homeostasis, and has been shown to play a role in the regulation of glial proliferation, neuronal differentiation, maturation as well as other neuroprotective actions at very low extracellular concentrations (Michetti et al., 2002). When present at higher (micromolar) levels, S100B is thought to have apoptotic and neurotoxic effects (Hu et al., 1997). S100B is usually limited to the central nervous system and only present at minimal concentrations in the peripheral circulation in normal subjects with intact blood brain barrier. Therefore, it has been used as a marker of blood brain barrier disruption and glial injury or death when released by injured astrocytes and detected in the peripheral circulation (Marchi et al., 2004; Michetti et al., 2002). The protein has a short half life and is excreted mainly in the urine (Marchi et al., 2004). Many studies have shown that levels of S100B are higher in the cord blood of growth restricted fetuses that had "brain sparing" redistribution blood flow pattern in utero (Gazzolo et al., 2002), as well as cord blood or urine of newborns who had hypoxic ischemic encephalopathy (HIE) (Distefano et al., 2009; Gazzolo et al., 2004; Nagdyman et al., 2001; Qian et al., 2009; Thorngren-Jerneck et al., 2004), those who developed severe adverse neurologic outcomes or died at 1 year of age after an episode of HIE at birth (Gazzolo et al., 2003), and those who were later diagnosed with CP or died (Park et al., 2004; Thorngren-Jerneck et al., 2004). Amniotic fluid and neonatal urine S100B levels have also been shown to be associated with fetal and neonatal death, respectively (Florio et al., 2004; Gazzolo et al., 2005).

NSE is a glycolytic enzyme localized primarily within neurons and neuroendocrine cells, and its release has been used as another marker of neurologic injury and an indicator of poor prognosis in multiple clinical scenarios including HIE (Celtik et al., 2004; Nagdyman et al., 2001; Nguyen et al., 2006; Verdu Perez et al., 2001). An increase in both NSE and S100B serum levels is associated with severe brain injury, worse neurologic outcomes and mortality (Distefano et al., 2009; Nguyen et al., 2006; Vos et al., 2004).

Animal and human studies suggest that infection and inflammation lead to fetal inflammatory response, and that this inflammation is associated with brain injury and subsequent development of CP (Clark et al., 2008; Yoon et al., 2000). The host's defense to an inflammatory insult involves a group of intracellular proteins called damage-associated molecular pattern molecules or DAMPs, such as S100B (Lotze et al., 2007; Medzhitov 2008). When released into the extracellular milieu secondary to cellular injury, these DAMPs, including S100B, activate the receptor for advanced glycation end-products (RAGE) (Buhimschi et al., 2009, Lotze et al., 2007). Binding of ligands to RAGE results in activation of multiple cellular signaling cascades mediated by NFKB, which in turn amplifies cell dysfunction and tissue damage (Buhimschi et al., 2009; Lotze et al., 2007). A naturally occurring soluble truncated variant of RAGE (sRAGE) is thought to act as a decoy receptor for RAGE leading to inhibition of its activity. (Buhimschi et al., 2009; Schlueter et al., 2003; Yonekura et al., 2003) sRAGE has been proposed as a marker of RAGE axis activation. Fetal systemic concentrations of sRAGE are inversely related to the intensity of the fetal inflammatory response. sRAGE consumption is associated with tissue damage and organ failure in fetuses who mount a robust inflammatory response. (Buhimschi et al., 2009)

The major strength of this study is that it was nested in a multicenter trial where the outcomes were clearly defined and rigorously ascertained, and the data and specimens carefully collected in a standardized fashion. On the other hand, with the available sample 
size, this study had limited power to detect differences in individual outcomes or within groups such as GA categories at birth, infant gender, ethnicity/race, or development of chorioamnionitis, or for particular types and/or severity of CP; or to refute the possible role of S100B or RAGE pathway in tissue injury leading to neurologic damage. Other limitations to the study include that we only measured total sRAGE. Other isoforms of sRAGE (e.g. esRAGE) exist, participate to the total pool of sRAGE, but were not investigated in this study. Additionally we did not investigate the inflammatory or acid-base status of the fetus at birth.

The findings from our study do not refute the hypothesis that the development of CP may be secondary to a prenatal and/or intrinsic brain injury or susceptibility. Because of the kinetics of some of these markers, measuring these markers at birth may not highlight their role in the pathophysiology of insults that may have occurred earlier in utero. Also, the relation between S100B and sRAGE with CP may be compartment specific. Systemic concentrations may not reflect brain parenchymal concentrations/activity. In addition, the final clinical outcome of neonates at risk of developing $\mathrm{CP}$ or other long term neurodisabilities could be influenced by the interaction of the neonates with the postnatal environment.

In conclusion, after controlling for $\mathrm{GA}$ and $\mathrm{MgSO}_{4}$ treatment, we did not find the umbilical cord blood markers studied to be useful in differentiating neonates who developed $\mathrm{CP}$ or suffered death from those who did not.

\section{Acknowledgments}

The authors wish to thank the following subcommittee members who participated in protocol development and coordination between clinical research centers (Allison T. Northen, M.S.N, R.N.,), protocol/data management and statistical analysis (Elizabeth Thom, Ph.D), and protocol development and oversight (Karin Nelson, M.D.).

The project described was supported by grants from the Eunice Kennedy Shriver National Institute of Child Health and Human Development (NICHD) [HD27869, HD34208, HD34116, HD40544, HD27915, HD34136, HD21414, HD27917, HD27860, HD40560, HD40545, HD40485, HD40500, HD27905, HD27861, HD34122, HD40512, HD53907, HD34210, HD21410, HD36801, HD19897] MO1-RR-000080, and by the National Institute of Neurological Disorders and Stroke (NINDS) and does not necessarily represent the official views of the NICHD, NINDS, or the National Institutes of Health.

\section{Appendix}

In addition to the authors, other members of the Eunice Kennedy Shriver National Institute of Child Health and Human Development Maternal-Fetal Medicine Units Network are as follows:

University of Texas Medical Branch, Galveston, TX - G.D.V. Hankins, T. Wen, L.A. Goodrum, G.R. Saade, G.L. Olson, H.M. Harirah, E. Martin

University of Alabama at Birmingham, Birmingham, AL - J.C. Hauth, A. Northen, T. HillWebb, S. Tate, K. Nelson, F. Biasini

University of Utah, Salt Lake City, UT - L. Fullmer (Utah Valley Regional Medical Center), K. Anderson, A. Guzman (McKay-Dee Hospital), M. Jensen, L. Williams

University of Texas Southwestern Medical Center, Dallas, TX - K. Leveno, M.L. Sherman, J. Dax, L. Faye-Randall, C. Melton, E. Flores

Case Western Reserve University-MetroHealth Medical Center, Cleveland, OH - M. Collin, G. VanBuren, C. Milluzzi, M. Fundzak, C. Santori 
The Ohio State University, Columbus, $\mathrm{OH}$ - F. Johnson, M.B. Landon, C. Latimer, V. Curry, S. Meadows

Thomas Jefferson University, Philadelphia, PA - A. Sciscione, M.M. DiVito, M. Talucci, S. Desai, D. Paul

University of Tennessee, Memphis, TN - B.M. Sibai, R. Ramsey, W. Mabie, L. Kao, M. Cassie

Wayne State University, Detroit, MI - G.S. Norman, D. Driscoll, B. Steffy, M.P.

Dombrowski

Wake Forest University Health Sciences, Winston-Salem, NC-M. Harper, P.J. Meis, M. Swain, K. Klinepeter, M. O'Shea, L. Steele

University of North Carolina at Chapel Hill, Chapel Hill - K.J. Moise, Jr., S. Brody, J. Bernhardt, K. Dorman

University of Texas Health Science Center at Houston, Houston, TX - L.C. Gilstrap, III, M.C Day, E. Gildersleve, F. Ortiz, M. Kerr

Columbia University, New York, NY - F. Malone, V. Pemberton, L. Paley, C. Paley, S. Bousleiman, V. Carmona

Brown University, Providence, RI - M. Carpenter, J. Tillinghast, D. Allard, B. Vohr, L. Noel, K. McCarten

University of Cincinnati, Cincinnati, $\mathrm{OH}$ - M. Miodovnik, N. Elder, W. Girdler, T. Gratton

University of Chicago, Chicago, $I L$ - A.H. Moawad, M. Lindheimer, P. Jones

University of Miami, Miami, FL - F. Doyle, C. Alfonso, M. Scott, R. Washington

Northwestern University, Chicago, IL - G. Mallett, M. Ramos-Brinson., P. Simon

University of Texas at San Antonio, San Antonio, TX - O. Langer, E. Xenakis, D. Conway, M. Berkus

University of Pittsburgh, Pittsburgh, PA - S. Caritis, T. Kamon, M. Cotroneo, C. Milford

The George Washington University Biostatistics Center - E.A. Thom, B. Jones-Binns, M. Cooney, M. Fischer, S. McLaughlin, K. Brunette, E. Fricks

National Institute of Neurological Disorders and Stroke, Bethesda, MD - K.B. Nelson

Eunice Kennedy Shriver National Institute of Child Health and Human Development, Bethesda, MD - S. Tolivaisa, D. McNellis, C. Catz, K. Howell

MFMU Network Steering Committee Chair (University of Pittsburgh, Pittsburgh, PA) — J. Roberts

\section{References}

American College of Obstetricians and Gynecologists and the American Academy of Pediatrics (ACOG \& AAP). Neonatal Encephalopathy and Cerebral Palsy: Defining the Pathogenesis and 
Pathophysiology. Washington, DC: American College of Obstetricians and Gynecologists; September. 2003

Buhimschi CS, Baumbusch MA, Dulay AT, Oliver EA, Lee S, Zhao G, et al. Characterization of RAGE, HMGB1, and S100 beta in inflammation-induced preterm birth and fetal tissue injury. Am J Pathol. 2009; 175:958-75. [PubMed: 19679874]

Celtik C, Acunas B, Oner N, Pala O. Neuron-specific enolase as a marker of the severity and outcome of hypoxic ischemic encephalopathy. Brain Dev. 2004; 26:398-402. [PubMed: 15275704]

Clark SM, Ghulmiyyah LM, Hankins GD. Antenatal antecedents and the impact of obstetric care in the etiology of cerebral palsy. Clin Obstet Gynecol. 2008; 51:775-86. [PubMed: 18981802]

Distefano G, Currei S, Betta P, Li Volti G, Cilauro S, Alessandro F, et al. Perinatal asphyxia in preterm neonates leads to serum changes in protein S-100 and neuron specific enolase. Curr Neurovasc Res. 2009; 6:110-116. [PubMed: 19442160]

Florio P, Michetti F, Bruschettini M, Lituania M, Bruschettini P, Severi FM, et al. Amniotic fluid S100B protein in mid-gestation and intrauterine fetal death. Lancet. 2004; 364:270-272. [PubMed: 15262105]

Gazzolo D, Marinoni E, Di Iorio R, Lituania M, Bruschettini PL, Michetti F. Circulating S100 $\beta$ Protein Is Increased in Intrauterine Growth-Retarded Fetuses. Pediatr Res. 2002; 51:215-219. [PubMed: 11809917]

Gazzolo D, Marinoni E, Di Iorio R, Lituania M, Bruschettini PL, Kornacka M, et al. Measurement of Urinary S100B Protein Concentrations for the Early Identification of Brain Damage in Asphyxiated Full-term Infants. Arch Pediatr Adolesc Med. 2003; 157:1163-116. [PubMed: 14662567]

Gazzolo D, Marinoni E, Di Iorio R, Bruschettini M, Kornacka M, Lituania M, et al. Urinary S100B protein measurements: A tool for the early identification of hypoxic-ischemic encephalopathy in asphyxiated full-term infants. Crit Care Med. 2004; 32:131-136. [PubMed: 14707571]

Gazzolo D, Florio P, Ciotti S, Marinoni E, Di IR, Bruschettini M, et al. S100B protein in urine of preterm newborns with ominous outcome. Pediatr Res. 2005; 58:1170-1174. [PubMed: 16306188]

Hagberg B, Hagberg G, Beckung E, Uvebrandt P. Changing panorama of cerebral palsy in Sweden:VIII. Prevalence and origin in the birth year period 1991-1994. Acta Paediatr. 2001; 90:271-7. [PubMed: 11332166]

Hu J, Ferreira A, Van Eldik LJ. S100b induces neuronal death through nitric oxide release from astrocytes. J Neurochem. 1997; 69:2294-2301. [PubMed: 9375660]

Kaukola T, Satyaraj E, Patel DD, Tchernev VT, Grimwade BG, Kingsmore SF, et al. Cerebral palsy is characterized by protein mediators in cord serum. Ann Neurol. 2004; 55:186-194. [PubMed: 14755722]

Lotze MT, Zeh HJ, Rubartelli A, Sparvero LJ, Amoscato AA, Washburn NR, et al. The grateful dead: damage-associated molecular pattern molecules and reduction/oxidation regulate immunity. Immunol Rev. 2007; 220:60-81. [PubMed: 17979840]

Marchi N, Cavaglia M, Fazio V, Bhudia S, Hallene K, Janigro D. Peripheral markers of blood-brain barrier damage. Clinica Chimica Acta. 2004; 342:1-12.

Medzhitov R. Origin and physiological roles of inflammation. Nature. 2008; 454:428-435. [PubMed: 18650913]

Michetti F, Gazzolo D. S100B protein in biological fluids: a tool for perinatal medicine. Clin Chem. 2002; 48:2097-2104. [PubMed: 12446464]

Nagdyman N, Komen W, Ko HK, Muller C, Obladen M. Early biochemical indicators of hypoxicischemic encephalopathy after birth asphyxia. Pediatr Res. 2001; 49:502-506. [PubMed: 11264433]

Nguyen DN, Spapen H, Su F, Schiettecatte J, Shi L, Hachimi-Idrissi S, et al. Elevated serum levels of S100- $\beta$ protein and seuron-specific enolase are associated with brain injury in patients with severe sepsis and septic shock. Crit Care Med. 2006; 34:1967-74. [PubMed: 16607230]

Paneth N, Hong T, Korzeniewski S. The descriptive epidemiology of cerebral palsy. Clin Perinatol. 2006; 33:251-67. [PubMed: 16765723]

Park ES, Park CI, Choi KS, Choi IH, Shin JS. Overexpression of S100 $\beta$ protein in children with cerebral palsy or delayed development. Brain \& dev. 2004; 26:190-196. 
Perlman JM. Interventions strategies for neonatal hypoxic-ischemic cerebral injury. Clin Ther. 2006; 28:1353-65. [PubMed: 17062309]

Qian J, Zhou D, Wang YW. Umbilical artery blood $\mathrm{S} 100 \beta$ protein: a tool for the early identification of neonatal hypoxic-ischemic encephalopathy. Eur J Pediatr. 2009; 168:71-77. [PubMed: 18398623]

Ramaswamy V, Horton J, Vandermeer B, Buscemi N, Miller S, Yager J. Systematic review of biomarkers of brain injury in term neonatal encephalopathy. Pediatr Neurol. 2009; 40:215-226. [PubMed: 19218035]

Rouse DJ, Hirtz DG, Thom E, et al. A randomized trial of magnesium sulfate for the prevention of cerebral palsy. NEJM. 2008; 359:895-905. [PubMed: 18753646]

Saigal S, Doyle LW. An overview of mortality and sequelae of preterm birth from infancy to adulthood. Lancet. 2008; 371:261-69. [PubMed: 18207020]

Schlueter C, Hauke S, Flohr AM, Rogalla P, Bullerdiek J. Tissue-specific expression patterns of the RAGE receptor and its soluble forms--a result of regulated alternative splicing? Biochim Biophys Acta. 2003; 1630:1-6. [PubMed: 14580673]

Thorngren-Jerneck K, Alling C, Herbst A, Amer-Wahlin I, Marsal K. S100 protein in serum as a prognostic marker for cerebral injury in term newborn infants with hypoxic ischemic encephalopathy. Pediatr Res. 2004; 55:406-412. [PubMed: 14630979]

Verdu Perez A, Falero MP, Arroyos A, Estevez F, Felix V, Lopez Y, et al. Blood neuronal specific enolase in newborns with perinatal asphyxia. Rev Neurol. 2001; 32:714-7. [PubMed: 11391504]

Vos PE, Lamers KJ, Hendriks JC, et al. Glial and neuronal proteins in serum predict outcome after severe traumatic brain injury. Neurology. 2004; 62:1303-1310. [PubMed: 15111666]

Winter S, Autry A, Boyle C, Yeargin-Allsopp M. Trends in the prevalence of cerebral palsy in a population-based study. Pediatrics. 2002; 110:1220-1225. [PubMed: 12456922]

Yonekura H, Yamamoto Y, Sakurai S, Petrova RG, Abedin MJ, Li H, et al. Novel splice variants of the receptor for advanced glycation end-products expressed in human vascular endothelial cells and pericytes, and their putative roles in diabetes-induced vascular injury. Biochem J. 2003; 370:1097-109. [PubMed: 12495433]

Yoon BH, Romero R, Park JS, Kim CJ, Kim SH, Choi JH, et al. Fetal exposure to an intrauterine inflammation and the development of cerebral palsy at the age of three years. Am J Obstet Gynecol. 2000; 182:675-681. [PubMed: 10739529]

\section{Abbreviations}

$\begin{array}{ll}\text { CP } & \text { cerebral palsy } \\ \text { MgSO4 } & \text { magnesium sulfate } \\ \text { NSE } & \text { neuron-specific enolase } \\ \text { SRAGE } & \text { soluble form of the receptor for advanced glycation end-products } \\ \text { ELISA } & \text { enzyme-linked immunosorbent assay } \\ \text { GA } & \text { gestational age } \\ \text { pPROM } & \text { preterm premature rupture of membranes } \\ \text { HIE } & \text { hypoxic ischemic encephalopathy } \\ \text { DAMP } & \text { damage-associated molecular pattern molecules }\end{array}$


Research Highlights

- In the univariable analysis, umbilical cord serum concentrations of S100B were significantly higher in neonates who developed cerebral palsy compared with the control group

- In the univariable analysis, cord serum concentrations of the total soluble form of the receptor for advanced glycation end-products (sRAGE) were significantly lower in neonates who died compared with controls, and more perinatal death cases had sRAGE concentrations in the lowest quartile

- There were no differences in cord serum concentrations of neuron-specific enolase or sRAGE between neonates who developed cerebral palsy and controls

- None of the studied biomarkers was associated with the composite outcome of death or cerebral palsy.

- Our findings do not negate that markers of neurologic damage leading to cerebral palsy may be detected in the fetus at birth 
Table 1

Maternal demographic and obstetric characteristics of cases and controls

\begin{tabular}{|c|c|c|c|}
\hline & $\underset{(n=41)}{\text { Cases* }}$ & $\underset{(\mathbf{n}=82)}{\text { Controls }}$ * & P-value \\
\hline Maternal age (yrs) & $25.8 \pm 6.0$ & $26.2 \pm 5.9$ & 0.70 \\
\hline Ethnicity & & & 1.0 \\
\hline African American & $21(51.2)$ & $42(51.2)$ & \\
\hline Caucasian & $16(39.0)$ & $33(40.2)$ & \\
\hline Hispanic & $3(7.3)$ & $6(7.3)$ & \\
\hline Other & $1(2.4)$ & $1(1.2)$ & \\
\hline Education (yrs) & $12.0 \pm 1.8$ & $12.3 \pm 2.4$ & 0.24 \\
\hline Smoked during pregnancy & $13(31.7)$ & $22(26.8)$ & 0.57 \\
\hline Alcohol during pregnancy & $3(7.3)$ & $6(7.3)$ & 1.0 \\
\hline Drug use during pregnancy & $6(14.6)$ & $9(11.0)$ & 0.57 \\
\hline Married / living with partner & $17(41.5)$ & $46(56.1)$ & 0.13 \\
\hline Nulliparous & $11(26.8)$ & $30(36.6)$ & 0.28 \\
\hline In $\mathrm{MgSO}_{4}$ group & $18(43.9)$ & $39(47.6)$ & 0.70 \\
\hline pPROM & $34(82.9)$ & $68(82.9)$ & 1.0 \\
\hline Antenatal corticosteroids (any) & $41(100.0)$ & $78(95.1)$ & 0.30 \\
\hline Mode of delivery: & & & 0.09 \\
\hline SVD & $20(48.8)$ & $53(64.6)$ & \\
\hline Operative vaginal delivery & $0(0.0)$ & $3(3.7)$ & \\
\hline Cesarean & $21(51.2)$ & $26(31.7)$ & \\
\hline Preeclampsia & $2(4.9)$ & $1(1.2)$ & 0.26 \\
\hline Chorioamnionitis, clinical & $9(22.0)$ & $11(13.4)$ & 0.23 \\
\hline
\end{tabular}

* Cases were infants who developed cerebral palsy or died before they would be evaluated.

Controls were infants who survived until 2 years of age without developing cerebral palsy.

Data presented as mean $\pm \mathrm{SD}$ or $\mathrm{n}(\%)$

$\mathrm{MgSO}_{4}=$ magnesium sulfate, $\mathrm{pPROM}=$ preterm premature rupture of membranes, $\mathrm{SVD}=$ spontaneous vaginal delivery 
Table 2

Neonatal characteristics of cases and controls

\begin{tabular}{|l|c|c|c|}
\hline & $\begin{array}{c}\text { Cases * } \\
(\mathbf{n = 4 1 )}\end{array}$ & $\begin{array}{c}\text { Controls * } \\
(\mathbf{n = 8 2})\end{array}$ & P-value \\
\hline Gestational age at birth (wks) & $27.9 \pm 2.7$ & $30.5 \pm 2.6$ & $<0.001$ \\
\hline Birth weight (g) & $1134 \pm 444$ & $1574 \pm 532$ & $<0.001$ \\
\hline SGA & $1(2.4)$ & $2(2.4)$ & 1.0 \\
\hline Male gender & $25(61.0)$ & $50(61.0)$ & 1.0 \\
\hline 1 minute Apgar score $<3$ & $12(29.3)$ & $5(6.1)$ & $<0.001$ \\
\hline 5 minutes Apgar score $<7$ & $15(36.6)$ & $9(11.0)$ & $<0.001$ \\
\hline Newborn sepsis $£$ & $16(39.0)$ & $7(8.5)$ & $<0.001$ \\
\hline
\end{tabular}

Cases were infants who developed cerebral palsy or died before they would be evaluated. Controls were infants who survived until 2 years of age without developing cerebral palsy.

Data presented as mean $\pm \mathrm{SD}$ or $\mathrm{n}(\%)$

$\mathrm{SGA}=$ small for gestational age.

${ }^{£}$ Early or late onset, culture proven sepsis 


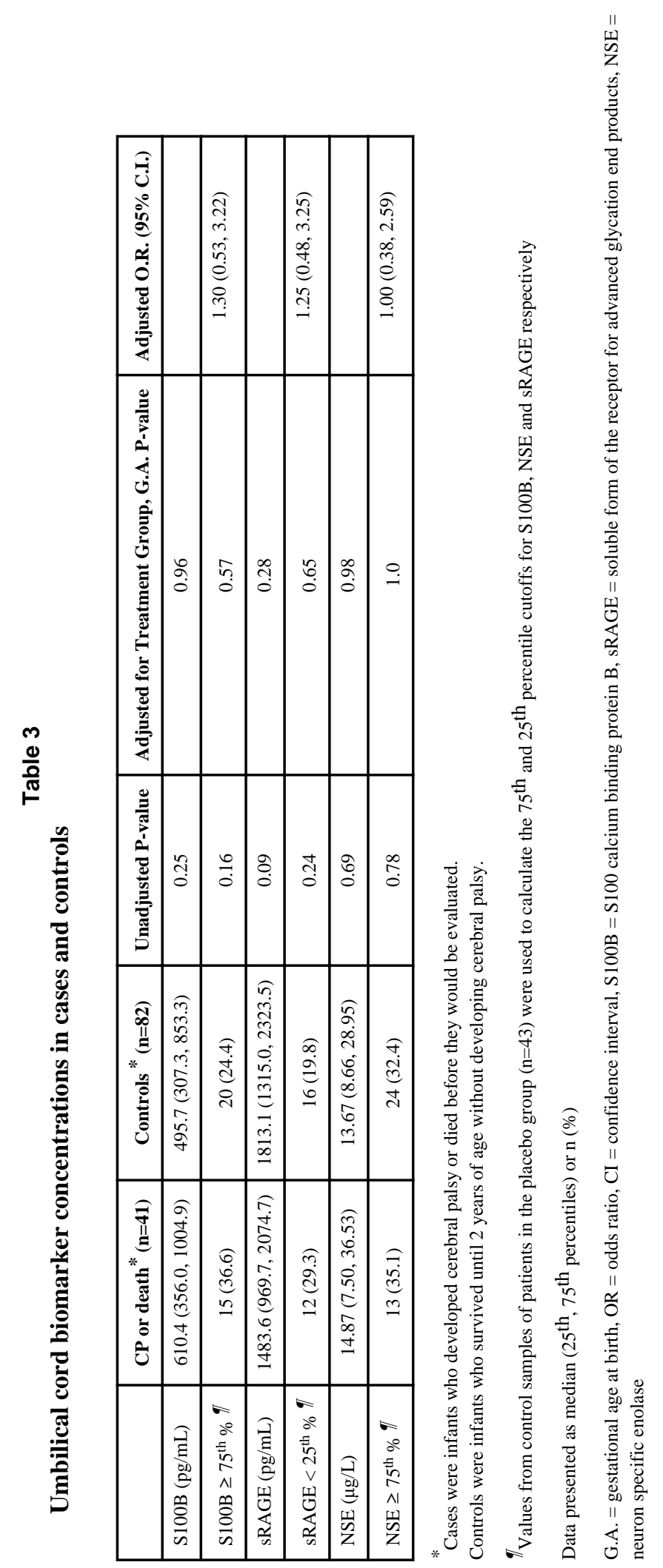

Int J Dev Neurosci. Author manuscript; available in PMC 2012 December 1. 


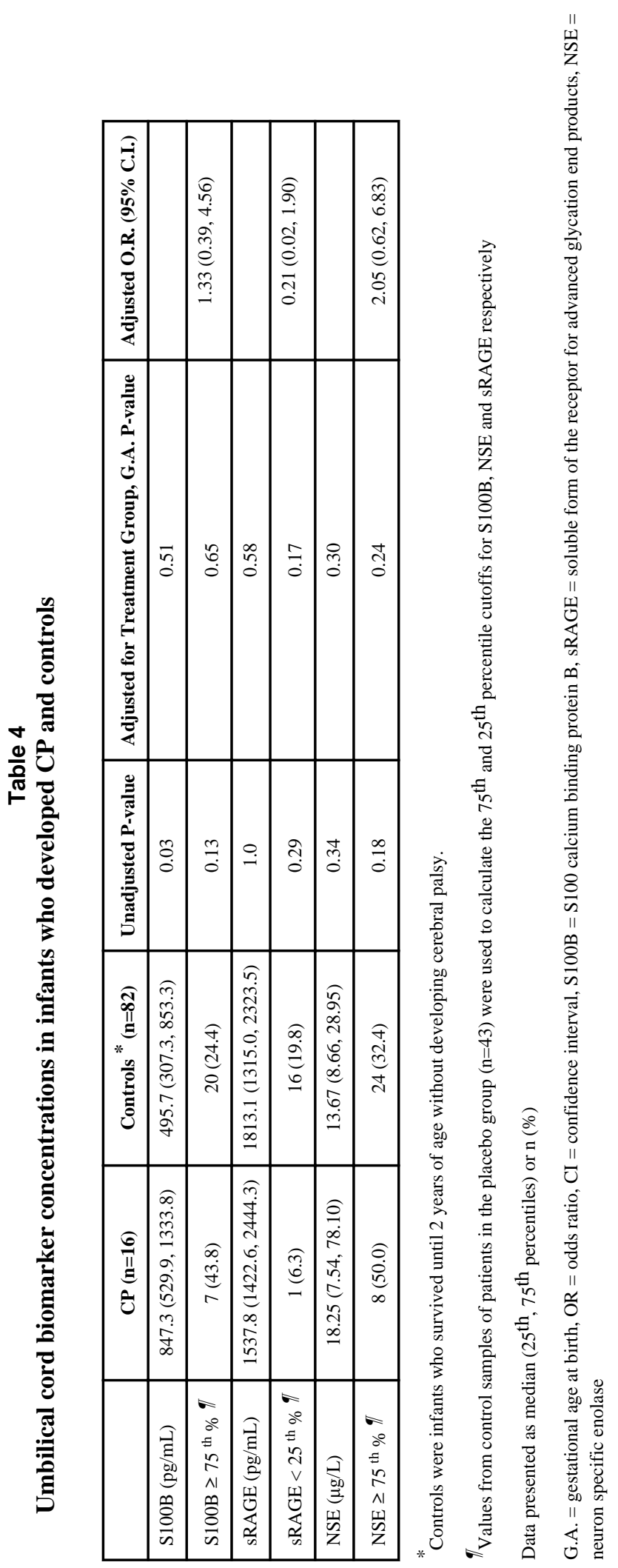

Int J Dev Neurosci. Author manuscript; available in PMC 2012 December 1. 


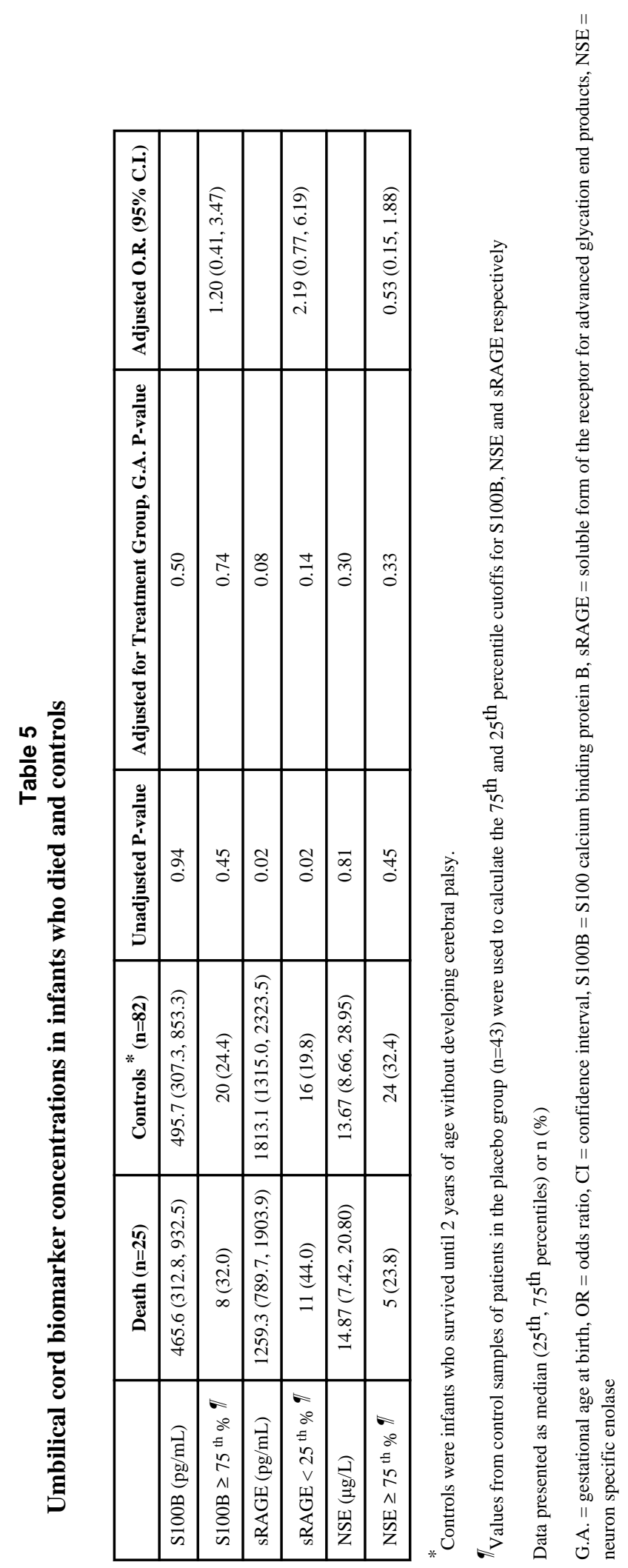

Int J Dev Neurosci. Author manuscript; available in PMC 2012 December 1. 


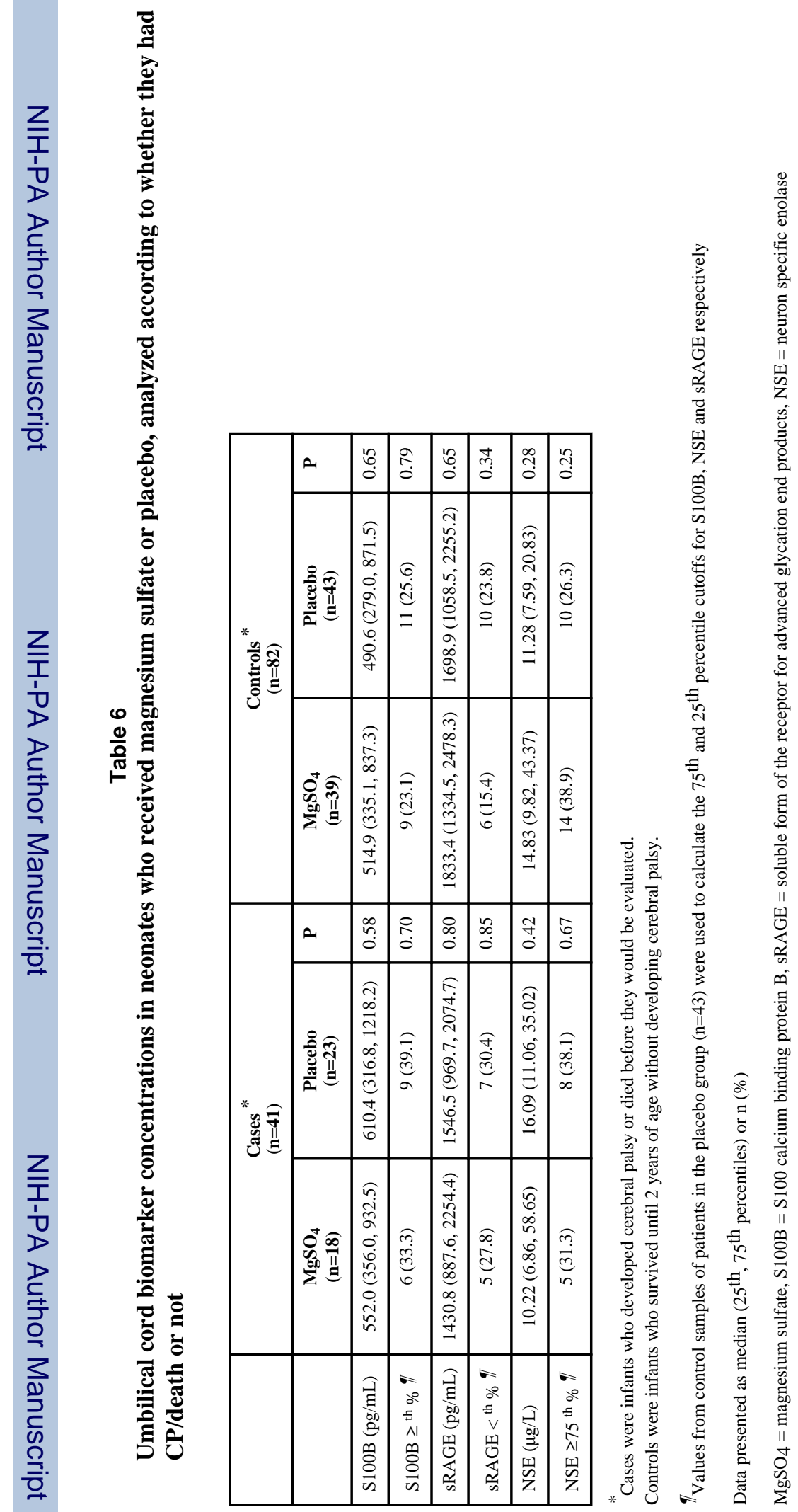

Int J Dev Neurosci. Author manuscript; available in PMC 2012 December 1. 